\title{
Who cares? The lost legacy of Archie Cochrane
}

Clemet Askheim, Institute of health and society, Faculty of Medicine, University of Oslo, NORWAY

Tony Sandset, Department of cultural studies and oriental languages, Faculty of humanities, University of Oslo, NORWAY

Eivind Engebretsen, Institute of health and society, Faculty of Medicine, University of Oslo BOX 1130 Blindern, 0318 OSLO, NORWAY (Corresponding author)

eivind.engebretsen@medisin.uio.no

Phone / fax: +4722845352 / +4722850590

Key words: Evidence-based medicine, history of medicine, history of science, Cochrane, health policy

Word count (excl. title page, abstract \& references): 4934 


\title{
Who cares? The lost legacy of Archie Cochrane
}

\author{
Abstract \\ Over the last 20 years the evidence-based medicine (EBM) movement has sought to develop \\ standardized approaches to patient treatment by drawing on research results from randomized \\ controlled trials. The Cochrane Collaboration and its eponym, Archie Cochrane, have become \\ symbols of this development, and Cochrane's book Effectiveness and Efficiency from 1972 is \\ often referred to as the first sketch of what was to become EBM. In this article we claim that \\ this construction of EBM's historical roots is based on a selective reading of Cochrane's text. \\ Through a close reading of this text we show that the principal aim of modern EBM, namely \\ to warrant clinical decisions based on evidence drawn from randomized controlled trials \\ (RCTs) is not part of Cochrane's original project. He had more modest ambitions for what \\ RCTs can accomplish, and, more importantly, he was more concerned with care and equality \\ than are his followers in the EBM movement. We try to reconstruct some of Cochrane's lost \\ legacy and to articulate some of the important silences in Effectiveness and Efficiency. From \\ these clues it might be possible, we argue, to remodel EBM in a broader, more pluralistic, \\ more democratic and less authoritarian manner.
}


Since the term evidence-based medicine (EBM) was introduced in 1991 by Gordon Guyatt,[1] the movement has grown both in scope and influence.[2, 3] From the margins of epidemiology and statistics, EBM has become the hegemonic way of thinking and practicing within the health sciences in general. However, this ascent has been accompanied by a narrowing of the practical understanding and usage of EBM, from the broad outline given by Gyatt et al. in 1992 [4] and Sackett et al. in 1996 [5] to a more rigid and confined meaning.[6] Although the EBM framework maintains that clinical practice shall be based on integration of research evidence with clinical expertise and patient preferences, the main emphasis has been on developing standardized methods for making use of research from randomized controlled trials (RCTs): 'Providing evidence-based care to patients involves turning a clinical problem into an answerable question and then systematically searching for the best evidence, critically appraising the evidence, and using the evidence as the basis for clinical decisions to solve the problem'.[7] The principal tools for supporting this approach are systematic reviews of clinical trials pioneered by the Cochrane Collaboration [8] and, more recently, clinical practice recommendations in the form of clinical guidelines. Although such approaches and tools are important for making current research more accessible for clinicians, it has been pointed out that their hegemony threatens to marginalize other more tacit forms of knowledge such as clinical intuition and, more broadly, the care dimension of clinical work. [9] Such concerns have inspired researchers to call for a 'renaissance' and a 'return to the movement's founding principles - to individualize evidence and share decisions through meaningful conversations in the context of a humanistic and professional clinician-patient relationship'.[10] In this paper we will contribute to this call for a 'renaissance' by returning to one of the founding texts within EBM, the book Effectiveness and Efficiency (hereafter $\mathrm{EE}$ ), written in 1972 by the British epidemiologist who has given his name to the Cochrane Collaboration, Archibald Cochrane.[11]

EE is often referred to as the first sketch of what was to become EBM.[12,13] However, as we will claim, this construction of EBM's historical roots is based on a misreading of Cochrane's text. Not only does Cochrane have a lot more modest ambitions for what randomized controlled trials can accomplish than his followers claim in his name,[14] he is also, more concerned with the care dimension of medicine, and with equality, than his followers in the EBM movement. 
Through a close reading of EE, we will bring out 'a difference within the work by demonstrating that it is other than it is', to adopt a phrase from the literary theorist Pierre Macherey (p. 8).[15] First, we will try to demonstrate that the dominant understanding of EBM is based on a selective reading of Cochrane's text. Second, we will show how this reading leads to a "purification" of medicine as science, largely excluding care. Finally we point towards an alternative reading of Cochrane, more in line with a revised understanding of EBM as advocated by Greenhalgh et al.[10]

We are not the first to have found discontinuities and paradoxes in EE and its reception. Richard Ashcroft identifies several 'unfamiliar' elements in the text when he compares what Cochrane actually says to the 'distorted' Cochrane coming out of the debates surrounding EBM.[16] Wendy Rogers finds Cochrane's concern for care 'puzzling', given his explicit focus on cure.[17] Their observations are very much in line with our own, but neither of them undertakes a close reading of the text, nor do they seem to fully capture the reformatory potential inherent in Cochrane's text. In a recent review on EBM and healthcare, Ana Fernandez and her colleagues also perceive Cochrane in ways similar to ours. They point to the narrowing of Cochrane's broad health system's perspective in later EBM, and his interest in the aspects of care rather than cure.[18] By following Macherey and paying attention to what Cochrane doesn't say, we try to also measure the silences in EE: 'what the work cannot say is important, because there the elaboration of the utterance is acted out, in a sort of journey to silence'(p. 97).[15] Thereby we hope to contribute to a more thorough reading than what has previously been done.

\section{Forgotten origins}

As Cochrane explicitly states in his introduction, EE was a commissioned work, the purpose of which was to evaluate the National Health Service (NHS) in the UK. This means that it was written in a specific context with a specific goal, and against a certain backdrop, namely concerns over the effective management of the NHS. Cochrane shared these concerns, and the book must first and foremost be read as an enlightenment project containing welfare-oriented, humanistic and epidemiological arguments for a more rational public administration of the health services.

In the preface of EE Cochrane introduces three concepts that he intends to use throughout the evaluation: 'effectiveness', 'efficiency' and 'equality'. Effectiveness concerns 'the effect of a 
particular medical action in altering the natural history of a particular disease for the better' (p. 2),[11] efficiency relates to cost effectiveness and getting more and better health per pound, and equality means offering the same health service, understood in its broadest sense, to all. Cochrane devotes most of the book to effectiveness and efficiency, which for him are intimately related, but they are not, he admits, applicable to NHS in its entirety.[11] 'I see the NHS, rather crudely, as supplying on the one hand therapy, and on the other board and lodging and tender, loving, care. My two indices [effectiveness and efficiency] are very relevant to the former, but only to a limited extent to the latter. I needed another index with which to compare the two branches of the NHS and add a little humanity to my approach. Returning to my early enthusiasm for the idea of an NHS, I soon discovered what I wanted: equality' (p. 3).[11] In separating 'therapy', or cure, from 'board and lodging and tender loving care', he follows the standard division between curative medicine and medicine as care. He specifically includes diagnosis within cure, while prevention is a category of its own. We have tried to follow this division and when speaking about healthcare in general, 'which covers all the activities of the NHS'(p. 3),[11], we either use 'healthcare' or it is specified by the context. As we will come back to, Cochrane's idea of equality is linked to his concern for care: "There has been so little work done in the "care" section that I decided to discuss it under "Equality". Changes in the "standard of living" of that side of the NHS may well produce such marked changes that the evaluation of "care" is difficult until equality with the cure side has been achieved' (p. 3).[11]

For Cochrane, the question of effectiveness is closely tied to his famous praise of the RCT, but the following sentence seems widely ignored: 'It is in this sense that I use the word "effective" in this book, and I use it in relation to research results, as opposed to the results obtained when a therapy is applied in routine clinical practice in a defined community' (p. 2 , our emphasis).[11] Here he interestingly restricts his claims to research results and refrains from talking about effectiveness in relation to results obtained in everyday clinical practice. This explicit restriction in Cochrane's claim seems to be largely overlooked by those most eager to link their activities to his name and his legacy.[8, 19] The principal aim of modern EBM, namely to warrant clinical decisions based on evidence drawn from RCTs, is thus not part of Cochrane's original project.

In his chapter on 'evaluation of evidence' he is even more cautious in his praise of RCTs: 'the problem of evaluation is the first priority of the NHS and that for this purpose the RCT is 
much the most satisfactory in spite of its snags. The main job of medical administrators is to make choices between alternatives. To enable them to make the correct choices they must have accurate comparable data about the benefit and cost of the alternatives. These can really only be obtained by an adequately costed RCT' (p. 25).[11] The strength of RCTs applies first and foremost to evaluation of health services and is relevant mainly for medical administrators. The main goal of the indices 'effectiveness' and 'efficiency' is thus to reduce 'the marked economic inequalities between the "care" and "cure" sectors' (p. 78).[11]

Towards the end of EE, in making suggestions for future developments, Cochrane writes: 'Until we know from the results of RCTs which types of disease can be as well treated at home as in hospital estimates of possible savings are clearly subject to enormous error, but there does seem to be a real hope of saving sufficient money to pay for the economic rehabilitation of the "care" services' (p. 84).[11] As we can see, there is, for Cochrane, a connection between effectiveness (RCTs) and improvement of 'care'. In other words, 'he saw such trials as a means to disclose ineffective treatments, and in that way get more money for care to overcome inequalities in the health-care system' (p. 108).[20] This view of RCTs is a long way from later claims that RCTs are the universal gold standard of medical evidence.[20]

\section{Journey to silence}

Despite his explicit concern for care, he only touches briefly upon it in the book, in his discussion of 'equality'. For Cochrane, this is a practical limitation: 'I have devoted most of the space to an analysis of effectiveness and efficiency in the "cure" section, because so much more is known about it' (p. 3).[11] In retrospect, this self-imposed limit seems curiously defensive and circular; but worse, it has turned out to be self-fulfilling and even selfenergizing. And here is where later proponents of EBM have interpreted (consciously or unconsciously) Cochrane's practical delineation as a scientific demarcation. In Cochrane's understanding, the health service naturally includes care, but for the time being he will nevertheless focus on cure. But instead of gradually increasing focus on care and the quality of care, the methods starts to define the object, causing care to vanish from the world of EBM.

Cochrane describes three different kinds of output from the NHS: 'freedom from worry about the cost of medical treatment and care', 'increased equality between social classes and between different parts of the country' and 'improved care for those who cannot look after 
themselves' (p. 12).[11] He goes on to say that '[n]either of these lend themselves to detailed input/output studies but the third type of output, the "cure" or "therapeutic" output, can to some extent be looked at in this way' (p. 12 our emphasis).[11] Again, this becomes the reason for focusing on that aspect: 'not because I think cure is more important than care, but because I suspect there is a gross discrepancy between input and output in this sphere which needs investigating, and for which the information is beginning to become available' ( $p$. 12).[11] In our understanding of EBM, the overvaluing of RCTs (effectiveness) is related to the undervaluing of care. Or, more precisely, the former results in the latter. Previously, when the Cochrane Collaboration has been reproached for ignoring Cochrane's acknowledgment of the limitations of RCTs,[21] further relations to other foundational aspects of EBM have not been not sought.

Cochrane clearly wanted to improve the quality of care, believing this would happen through gradual scientification of the care dimension of medicine. Contrary to this expectation, however, the scientification has instead excluded care from the science of medicine. Implicitly or explicitly, this demarcation by way of methods and not object, leads to the following kind of reasoning: medicine is considered science because of the method applied to create its object of focus, cure. While care, which is harder to capture statistically, using purely quantitative techniques of epidemiology, is placed at the margins of what medicine is. Care as an object of medical epistemology change character in the hands of this quantitative scientification, whereas the original object of care slips away. It is not that care is unimportant, but it lies outside the realm of the methods available. Hence methods are allowed to define the object, rather than the object forcing methods to be developed.[22]

Cochrane's practical considerations should also be seen in connection with the tools of measurements and control that he had at his disposal. Cure can be measured; 'evidence' can be gauged and weighed by quantifying and making cure numerical. Care, on the other hand, seems to be less easy to measure with the same tools and by the same standards. It doesn't fit the cost-effective evaluating framework in the same way. Hence, the more EBM stresses RCTs, the more marginalized care becomes. Wittgenstein's postulate of 'what we cannot speak about we must pass over in silence' (p. 89)[23] could, in this setting, be read as 'since we cannot speak/measure care, we must pass over it in silence'. This silence, as we will argue, still lingers on within the framework of EBM. 


\section{The purification of medicine as science}

What Cochrane viewed as a temporary silence, because of the mission he had to accomplish and the state of evidence at the time, has become a permanent silence. Modern EBM seems to equate medicine as science and medicine as cure. When Cochrane's reservations about RCTs were forgotten, it paradoxically paved the way for the exclusion of care from the science of medicine as understood by EBM. The logic being that if it cannot be studied with the accepted methods of science, it is not science.

The demarcation that Cochrane unknowingly establishes is one that will later foreclose a science of care while enabling a discourse of cure. In Bruno Latour's framing we could say that this is due to cure's allegedly 'pure' logic, its 'evidential' frame of representation, while care belongs to a 'hybrid' space.[24] Here, purification, in the Latourian sense, means that not only have cure and care been accorded different positions within what can count as scientific medicine, but also, by way of Cochrane's ill-fated delineation, two different ontologies have been created. On the one hand, there is cure, which belongs to the realm of the scientific, while on the other hand, there is care, which belongs to the realm of the social.[24] Therefore EBM had from the outset, to discard the social side of medicine, where care is located, .

Essentially, Cochrane's practical limitation has led to the purification of care and what remains is cure as the hegemonic definition of medicine. Not only do the methods delineated (such as RCTs) become universal, but the very domain of cure becomes the gold standard for what medicine should do and be. If care is to enter the dominant scientific discourse of medicine, it must follow the same rules as 'cure' and be couched in the formulae of EBM. [25] Thus, care as an autonomous epistemological object and distinct part of the science of medicine is ruled out, and is instead forced to adopt the inappropriate parameters of 'effectiveness' and 'efficiency'.

\section{Quality or equality?}

Cochrane's mission statement shows us just what was left by the wayside when EBM was only being formulated as a proto discourse of care and cure. What was enabled and what was foreclosed in EE and its reception, points to the ways in which EBM seems unable to articulate a medical practice that is written according to the modalities of care. What follows is a complete disinterest in issues of equality, which were of utmost importance for Cochrane. 
He only devotes one chapter of EE, not even ten pages long, explicitly to equality, but the ethos of equality underlies the whole book.[26]

The obvious inequalities in the health services are usually framed in terms of different social backgrounds or regional differences, but Cochrane states: 'I am not concerned with quality of treatment but with quality of living' (p. 73).[11] As examples of what this might include in a hospital, he lists: 'food, heating, lighting, decoration, and comfort' (p. 73).[11] What he calls 'quality of treatment' would be what today is more commonly known as 'quality of care', as in health care in general. But in line with our argument, this tends to mean curative aspects more than care. [27] Cochrane points to 'the growing gap between the standard of living in an acute general hospital on the one hand and psychiatric, geriatric, and mentally deficient institutes on the other' (p. 73).[11] He admits that not much has been done in this respect, despite the fact that 'most of us know the probability that we, our relatives, and our friends may end our days in geriatric or psychiatric wards' (p. 73).[11] Finally comes his moral judgment that 'this sort of inequality is the least excusable and the most easily remedied of the many inequalities in the NHS' (p. 75).[11]

\section{From means to ends}

In an attempt to describe Cochrane's 'philosophy of medicine', Uffe Juul Jensen relates Cochrane's remarks on equality to his more general thoughts on medicine, science and politics.[26] He underlines Cochrane's belief in 'the relative unimportance of therapy in comparison with the recuperative power of the human body' (p. 5).[11] These remarks must be understood in the context of Cochrane's general task: improving effectiveness in the health services. If one can prove that therapy, or cure, is relatively unimportant, more resources could be spent on care or prevention. This is also why most of the book is devoted to effectiveness and efficiency: "the economic rehabilitation of the "care" services will need very considerable sums of money both in capital and expenditure and it is this money that we must look for by the scientific control of inflation' (p. 78).[11] If you can save money by excluding ineffective treatments (cure), more money could be spent on care, which would lead to increased equality across social classes, regions, diseases and so on.

With the purification of EBM and the removal of care from EBM's vocabulary, it becomes nearly impossible to even articulate issues of equality within the EBM discourse. If it is care it is not EBM, and if it is EBM it is no longer care. In contrast to Cochrane's social-democratic 
ideas of equality, the only way EBM can address equality is in terms of effectiveness of treatment.[28] Within the frame of EBM, and contrary to Cochrane's views, quality is conflated with effectiveness, and equality is reduced to a question of equal access to equal quality of treatment, or in other words, effectiveness. But what was a means (effectiveness and efficiency in the cure sector) for Cochrane has, in EBM, become an end. And what Cochrane considers ends (improved care and increased equality), have floated out of sight in EBM.

To sum up our argument so far: Contrary to popular belief, Cochrane does not advocate the general use of RCTs to measure everything. In contrast to what one might think, he is emphasizing care at the expense of cure. His main concern is equality, broadly understood as equal access to quality of living, which cannot be properly evaluated with either the standards of effectiveness or of efficiency, and thus not properly measured using only statistical techniques. Proponents of EBM nevertheless use Cochrane as their main figurehead, even though they generally value results from RCTs more highly than other types of knowledge. Instead of Cochrane's quality of living, EBM promotes general comparativeness using socalled utility-theory and 'quality of life' (QALY) measurements.[29] This marginalizes care by turning quality into quantity and by taking means for ends, leading EBM to largely ignore questions of equality, which are at best understood in terms of effectiveness of treatment across GPs and hospitals. In addition to 'measuring silences' in EE, we have also found a tendency to silence central aspects of the work within the very tradition which claims to follow Cochrane's legacy. In the process of appropriating Cochrane as a forerunner of EBM, they have purified EE, and left behind those 'hybrid' aspects that didn't fit in. So what happened to the lost legacy of Cochrane?

\section{Dialectic of enlightenment}

The ironic twist of Cochrane's legacy is that it started as critique and a vision for a more caring system of medicine, yet ended up delineating a system that, by its focus on a set of certain scientific methods, lead to the purification of science as cure and the relegation of care to a hybrid realm. Others have pointed at different, yet similar, paradoxes in the development of what has since become EBM.[30] Discussing questions of medical authority and whether 'science promotes democratic ends in medicine', Keld Thorgaard writes that: 'As the demand for democratization goes deeper, the idea that a more science-based medicine will promote democratic ends seems to be subverted by its own logic'. (p. 50).[31] And in a critical 
assessment of 'evidence' in EBM and the dogma of 'best available evidence', Alvan Feinstein and Ralph Horwitz, while acknowledging that EBM started as an anti-authoritarian movement in the spirit of Cochrane, wonder if it might end up as 'a new form of dogmatic authoritarianism' coming from 'Cochranian Oxford' (p. 535).[32] Symptomatically, in their first reaction to the establishment of the Cochrane Centre, The Lancet wrote an editorial which said: 'Specialty by specialty, authoritarianism based on mere seniority is giving way to authoritativeness based on randomized trials' (p. 1131).[14] Only three years later they took a more critical stand: 'The voice of evidence-based medicine has grown over the past 25 years or so from a subversive whisper to a strident insistence that it is improper to practice medicine of any other kind' $(p, 785)$.[33] It is a slippery slope from authoritativeness to authoritarianism, so how can we remain in the light of enlightenment?

In this slip, EBM suffers the fate 'reserved for triumphant thought', which is how Horkheimer and Adorno describe Enlightenment thinking: 'If it voluntarily leaves behind its critical element to become a mere means in the service of an existing order, it involuntarily tends to transform the positive cause it has espoused into something negative and destructive' (p. $\mathrm{Xv}$ ).[34] It is within these paradoxes and in this slippage that the call for an EBM renaissance must be located. But how can we prevent this 'return to real evidence-based medicine'[10] from just repeating history and ending up in the same place? How can we short-circuit the dialectic of enlightenment? If we are to succeed in revising EBM, we need to take seriously Horkheimer and Adorno's warning that 'even the most honorable reformer who recommends renewal in threadbare language reinforces the existing order he seeks to break by taking over its worn-out categorial apparatus and the pernicious power-philosophy lying behind it' ( $p$. xvii).[34] We will try to heed this warning and sketch an alternative historical grounding for the possible constitution of the 'real evidence-based medicine', based on the forgotten legacy of Cochrane.

\section{The articulation of a silence}

Macherey thinks that by articulating silences in a text, and changing the scientific discourse, we can establish new objects of science and thus possibilities for new knowledge: 'The act of knowing is not like listening to a discourse already constituted, a mere fiction which we have simply to translate. It is rather the elaboration of a new discourse, the articulation of a silence' (p. 6).[15] When critics of EBM have taken a renewed interest in Cochrane and EE, it has largely been a historic interest.[18, 35] Few have tried to extract fresh raw materials for a 
different discourse from the more hidden lodes in Cochrane's text. Juul Jensen is an exception when he tries to explicate Cochrane's 'philosophy of medicine' as a critique of EBM:

'Rational scientific and methodological principles are not sufficient for securing rational and humane health care. A philosophy reminding us of both our limited scientific possibilities limited in principle - and our personal responsibility is needed. It is one of Cochrane's great merits to have provided just that. It is to be regretted that many more people seem to have adopted his more technical advice concerning effectiveness and efficiency than have grasped the philosophical framework within which these standards are situated' (p, 31-2).[26] Our outline of a new discourse is based on this framework.

One of the most controversial and criticized elements of contemporary EBM is the so-called 'hierarchy of evidence' and the question of how different kinds of evidence should be weighted in both clinical and administrative decision making.[32, 36] This is also the aspect of EBM where Cochrane's alleged universal praise of RCTs is most prominent and common.[37] We have already pointed out that this is a highly selective and biased reading of Cochrane and that his actual claims are far more nuanced and modest, concerning mainly administrative evaluation. 'In writing this section in praise of the RCT I do not want to give the impression that it is the only technique of any value in medical research. This would, of course, be entirely untrue' (p. 25).[11] RCTs are not the only option, but they are one option, one method among many for approaching medicine as both curative and caring. There need not be a process of purification, through which 'methodological fetishism'[9] pushes care outside the science of medicine. Cochrane also points out that the NHS needs to explore care in order to have all the viable alternatives on the table and then compare those alternatives; the issue, then, seems to be to develop methods that can give these alternatives, methods that will lend themselves to say something about that which we cannot speak of. Methodological pluralism and evaluations of evidence that are not purely based on methodological criteria seem to be important starting points in this matter.[38, 39]

Clearly, the most suppressed aspect of EE is Cochrane's concern for care, and his insistence on the difference between a logic of cure and a logic of care. In the preface Cochrane states his own biases, one of which is his belief that 'cure is rare while the need for care is widespread, and that the pursuit of cure at all costs may restrict the supply of care' (p. 7).[11] Cochrane thinks care should be accorded more space, and that that space should be protected from the process of purification that we have analyzed in the above. He acknowledges that the 
NHS itself operates with two different sets of ontologies, one of therapy and one of care. The rehabilitation of care within medicine, and the protection of care from the colonizing logic of cure could be a starting point for a more nuanced and inclusive EBM.

Related to the suppression of care within EBM is the lack of concern with issues of equality, and thus ignorance of wider political issues. It is interesting to note that while EBM has adopted research designs and techniques from epidemiology, it has not adopted the focus or interests of traditional epidemiologists.[40, 41] Cochrane wrote EE before the rise of "clinical epidemiology' and he thinks like a classic epidemiologist when he writes: 'I accept the fact that clinical responsibility for the individual is a serious one, but so is the responsibility for the community' (p. 81).[11] One is tempted to ask whether EBM has lost some of Cochrane's 'humanity' and 'responsibility for the community' in its ascent towards 'triumphant thought'.

By taking on the 'responsibility for the community', and the issue of care and equality, Cochrane's enquiry focuses on the improvement of the health and wellbeing of the people in general, not on RCTs. This is the underlying social medicine side of Cochrane. Not only is care articulated, but more specifically, care as part of social justice. There is thus an epidemiological and social-democratic (social welfare) policy hidden in EE, whereas in the dominating understanding of EBM, one seem to live in a value-free world.[28] Michael Kelly and colleagues argue that EBM to a large extent ignores values in clinical settings, [35] and Gavin Mooney points out the general lack of clear objectives and values in EBM: '[T]oo often the presumption within EBM is that all that is relevant to the care of the patient is the health outcome', and then it follows that 'all the evidence that is needed is related to health' (p. 63).[28] Missing from this picture is Cochrane's 'quality of living' and Mooney's claim that '[e]quity at a community level may be valued for its own sake' (p. 65),[28] even if it leads to slightly less effective treatment and less efficiency. Mooney is afraid that: 'Ignoring equity in EBM, creates a risk that equity is sidelined as a social goal of health care' ( $p$. 68).[28] Cochrane clearly sees NHS as a social institution first and foremost, focusing on aspects of care and equality, but as long as EBM adheres to its current purified science of medicine, it will remain ignorant of the real world of social and political considerations.

If we want to restore the social side of medicine and give care back its own logic, we can find traces that support this position in EE. From these clues it might be possible to remodel EBM in a broader, more pluralistic, more democratic and less authoritarian manner. Edmund 
Husserl famously said that tradition is forgetfulness of origins, [42] and through the sedimentation of a certain distorted reading of EE, this seems to be the case with EBM and Cochrane. Not only is the context of the work forgotten (a suggested evaluation of the NHS), but Cochrane's own modesty and reservations also seem to be forgotten. We have thus tried to reconstruct some of Cochrane's lost legacy and to articulate some of the important silences in EE. 


\section{References}

1 Guyatt G. Evidence-Based Medicine. ACP J Club 1991;114:2.

2 Hooker RC. The rise and rise of evidence-based medicine. Lancet 1997;349: 1329-30.

3 Hitt J. Evidence-Based Medicine. New York Times Magazine 2001; $9^{\text {th }}$ December.

http://www.nytimes.com/2001/12/09/magazine/the-year-in-ideas-a-to-z-evidence-basedmedicine.html (accessed 10 jun 2016).

4 Guyatt G, Cairns J, Churchill D, et. al. Evidence-based medicine. A new approach to teaching the practice of medicine. JAMA 1992;268(17):2420-2425.

5 Sackett D, Rosenberg WMC, Muir Gray JA, Haynes RB, et. al. Evidence based medicine: what it is and what it isn't. BMJ 1996;312:71-2.

6 Timmermans S, Berg M. The gold standard: the challenge of evidence-based medicine and standardization in health care. Philadelphia, PA: Temple University Press 2003.

7 Tanjong-Ghogomu E, Tugwell P, Welch V. Evidence-Based Medicine and The Cochrane Collaboration. Bull NYU Hospital Jt Dis 2009;67(2):198-205.

8 Chalmers I, Dickersin K, Chalmers TC. Getting to grips with Archie Cochrane's agenda. BMJ 1992;305:786-7.

9 Greenhalgh T. Why do we always end up here? Evidence-based medicine's conceptual culde-sacs and some off-road alternative routes. J Prim Health Care 2012; 4(2):92-7.

10 Greenhalgh T, Howick J, Maskray N, et. al. Evidence based medicine: a movement in crisis? BMJ 2014;348:g3725.

11 Cochrane A. Effectiveness and efficiency. Random reflections on health services. London: The Nuffield Provincial Hospital Trust 1972.

12 Ashcroft RE. Current epistemological problems in evidence based medicine. J Med Ethics 2004;30:131-135.

13 Birch S, Gafni A. Evidence-based health economics. Answers in search of questions? In:

Kristiansen IS, Mooney G. Evidence-Based Medicine. In its place. London and NY:

Routledge 2004:50-61.

14 Anon. Cochrane's legacy. Lancet 1992;340(8828):1131-2.

15 Macherey P. A theory of literary production. Routledge. 2006

16 Ashcroft R. Doing the best we can. BioSocieties 2007; 2(1):141-3.

17 Rogers W. A book of its time. BioSocieties 2007; 2(1):143-5.

18 Fernandez A, et. al. Evidence-based medicine: is it a bridge too far? Health Res Policy Syst 2015; 13:66. doi: 10.1186 . 
19 Haynes B. What kind of evidence is it that Evidence-Based Medicine advocates want health care providers and consumers to pay attention to? BMC Health Serv Res 2002;2(1). 20 Jensen UJ. The struggle for clinical Authority: Shifting ontologies and the politics of evidence. BioSocieties 2007; 2:101-14.

21 Kristiansen IS, Mooney G. Evidence-Based Medicine. Method, collaboration, movement or crusade? In: Kristiansen IS and Mooney G. Evidence-Based Medicine. In its place. London and NY: Routledge 2004:1-19.

22 Despret V. Models and methods - sketch for a field study. Angelaki 2015; 20(2):37-52.

23 Wittgenstein L. Tractatus Logico-Philosophicus. London and NY: Routledge 2001.

24 Latour B. We have never been modern. Cambrigde MA: Harvard University Press. 1993. 25 Logsdon RG, McCurry SM and Teri L. Evidence-based interventions to improve quality of life for individuals with dementia. Alzheimers care today. 2007; 8(4):309-318.

26 Jensen UJ. Evidence, effectiveness and ethics. Cochrane's legacy. In: Kristiansen IS, Mooney G. Evidence-Based Medicine. In its place. London and NY: Routledge 2004.

27 Campbell SM, Roland MO and Buetow SA. Defining quality of care. Soc Sci Med. 2000; 51:1611-1625.

28 Mooney G. Evidence-based medicine. Objectives and values. In: Kristiansen IS, Mooney

G. Evidence-Based Medicine. In its place. London and NY:Routledge. 2004:66.

29 Brown MM, Brown GC, Sharma S and Garrett S. Evidence-based medicine, utilities, and quality of life. Curr Opin Ophthalmol 1999;10:221-226.

30 Hill GB. Archie Cochrane and his legacy. An internal challenge to physicians' autonomy? J Clin Epidemiol 2000(53):1189-92.

31 Thorgaard K. Is Evidence-based medicine about democratizing medical practice? Outlines - Critical Practice Studies 2014;15(1):49-62.

32 Feinstein A, Horwitz R. Problems in the 'evidence' of 'Evidence-based medicine'. Am J Med 1997;103:529-35.

33 Anon. Evidence-based medicine, in its place. Lancet 1995;346(8978):785.

34 Horkheimer M, Adorno T. Dialectic of Enlightenment. Stanford CA: Stanford University Press 2002.

35 Kelly MP, Heath I, Howick J and Greenhalgh T. The importance of values in evidencebased medicine. J Med Ethics 2015; 16(69): DOI 10.1186/s12910-015-0063-3.

36 Concato J, Shah N, Horwitz R. Randomized controlled trials, observational studies, and the hierarchy of research designs. N Engl J Med 2000;342:1887-92.

37 Sur R, Dahm P. History of evidence-based medicine. Indian J Urol 2011;27(4): 487-9. 
doi: 10.4103/0970-1591.91438.

38 Greenhalgh T, Annandale E, Aschcroft R, et. al. An open letter to The BMJ editors on qualitative research. BMJ 2016; 352:i563 doi: 10.1136.

39 Rawlins T. De testimonio: on the evidence for decisions about the use of therapeutic interventions. Lancet 2008;372:2152-61.

40 Little M. Assignment of meaning in epidemiology. Soc Sci Med 1998;47(9):1135-45.

41 Lomas J. Social capital and health: Implications for public health and epidemiology. Soc Sci Med 1998;47(9):1181-8.

42 Husserl E. The origin of geometry. In: Derrida J. Edmund Husserl's origin of geometry: an introduction. Lincoln and London: University of Nebraska Press 1989. 